\title{
A particle swarm optimization approach for components placement inspection on printed circuit boards
}

Chun-Ho Wu • Da-Zhi Wang - Andrew Ip •

Ding-Wei Wang - Ching-Yuen Chan .

Hong-Feng Wang

Published online: 24 December 2008

(C) Springer Science+Business Media, LLC 2008

\section{Erratum to: J Intell Manuf}

\section{DOI 10.1007/s10845-008-0140-2}

The original version of this article unfortunately contained a mistake. The following acknowledgment was missing from the article:

\begin{abstract}
Acknowledgment The authors wish to thank the Research Committee and the Department of ISE of the Hong Kong Polytechnic University for support in this research project (Project no. 1-45-56-RGNY).
\end{abstract}

The online version of the original article can be found under doi:10.1007/s10845-008-0140-2.

C.-H. Wu (凶) · D.-Z. Wang · A. Ip · D.-W. Wang ·

C.-Y. Chan - H.-F. Wang

Department of Industrial and Systems Engineering (ISE),

The Hong Kong Polytechnic University,

Hung Hom, Kowloon, Hong Kong

e-mail: jack.wu@polyu.edu.hk 